\title{
Carbonate Ion
}

National Cancer Institute

\section{Source}

National Cancer Institute. Carbonate Ion. NCI Thesaurus. Code C82598.

A polyatomic ion with formula of $\mathrm{CO}-$. 